\title{
Cellulose Nanocrystals Obtained from Rice By-Products and Their Binding Potential to Metallic Ions
}

\author{
Vanessa L. Albernaz, ${ }^{1,2}$ Graziella A. Joanitti, ${ }^{1,3}$ Cláudio A. P. Lopes, ${ }^{4}$ and Luciano P. Silva ${ }^{1,2}$ \\ ${ }^{1}$ Laboratório de Espectrometria de Msassa, Empresa Brasileira de Pesquisa Agropecuária (EMBRAPA)-Recursos \\ Genéicos e Biotecnologia, PqEB (Final W5), Asa Norte, 70770-917 Brasília, DF, Brazil \\ ${ }^{2}$ Programa de Pós-Graduação em Nanociência e Nanobiotecnologia, Universidade de Brasília, 70910-900 Brasília, DF, Brazil \\ ${ }^{3}$ Faculdade UnB Ceilândia, Universidade de Brasília, 72220-900 Ceilândia, DF, Brazil \\ ${ }^{4}$ Laboratório de Microscopia Eletrônica, Departamento de Biologia Celular, Universidade de Brasília, 70910-900 Brasília, DF, Brazil
}

Correspondence should be addressed to Luciano P. Silva; luciano.paulino@embrapa.br

Received 18 August 2015; Accepted 16 September 2015

Academic Editor: Tupei Chen

Copyright (C) 2015 Vanessa L. Albernaz et al. This is an open access article distributed under the Creative Commons Attribution License, which permits unrestricted use, distribution, and reproduction in any medium, provided the original work is properly cited.

\begin{abstract}
The present study aimed to develop and optimize a method to obtain cellulose nanocrystals from the agricultural by-products rice husk and straw and to evaluate their electrostructural modifications in the presence of metallic ions. First, different particle formation conditions and routes were tested and analyzed by spectrophotometry, dynamic light scattering (DLS), and Zeta potential measurements. Then, electrostructural effects of ions $\mathrm{Na}(\mathrm{I}), \mathrm{Cd}(\mathrm{II})$, and $\mathrm{Al}(\mathrm{III})$ on the optimized nanoparticles were analyzed by atomic force microscopy (AFM), scanning electron microscopy (SEM), and electrical conductivity (EC) assessments. The produced cellulose nanocrystals adopted a rod-like shape. AFM height distribution and EC data indicated that the nanocrystals have more affinity in binding with $\mathrm{Na}(\mathrm{I})>\mathrm{Al}(\mathrm{III})>\mathrm{Cd}(\mathrm{II})$. These data suggest that the use of these cellulose nanocrystals in the bioremediation field is promising, both in metal sorption from wastewater and as an alternative for water desalination.
\end{abstract}

\section{Introduction}

The use of agricultural by-products as sources of nanostructured compounds has been a subject of nanotechnological interest. This sustainable approach presents several benefits such as low-cost production, biodegradability, readily available resource, renewable nature, and easy processability [1].

Among the many compounds of interest, cellulose stands out by being one of the most abundant biopolymers. Cellulose fibres are the basis of plant cell wall foundation. They are formed by a network of microfibrils composed by cellulose chains. The microfibrils possess rigid and amorphous regions, and the rigid, or crystalline, region differs from the amorphous region by the high content of hydrogen bonds between the cellulose chains. The rigid region constitutes the socalled cellulose nanocrystals (CNCs), also known as cellulose whiskers. Thus, CNCs present very high mechanical strength and stiffness and are mostly used as reinforcing agents for micro- and nanocomposites [2].

Cellulose is mainly obtained from plants sources (e.g., wood and cotton) but can also be produced from bacteria, tunicates, and fungus [3]. Among the agricultural byproducts explored as sources of cellulose, such as sugar beet, sisal fibres, and barley straw, attention has been attracted to the rice by-products husk and straw. Rice is the largest produced cereal crop in the world and its by-products represent over half of the biomass volume in rice production and they are an abundant source of cellulose. Rice straw, for example, is composed of about $38.3 \%$ cellulose, $31.6 \%$ hemicellulose, $11.8 \%$ lignin, and $18.3 \%$ silica [4].

The most common method to obtain CNCs from plant sources is by sulphuric acid hydrolysis, which acts by breaking the cell wall, removing amorphous paracrystalline regions of cellulose, and leaving crystalline regions intact $[5,6]$. After 
hydrolysis, cellulosic surface becomes negatively charged and, therefore, is potentially able to interact with metal ions in aqueous solutions [7]. Furthermore, previous studies pointed out that rice husk and straw have an adsorption effect on removing heavy metals (i.e., cadmium) and even nitrate from wastewater [8-10].

Water pollution by discharge of toxic metals causes serious damage to the environment, and alternatives for bioremediation have been a major aim of scientific and technological research. The use of nanoscale biopolymers as a low-cost adsorbent for metal removal from water is advantageous over inorganic/mineral and macroscale materials, particularly due to the higher reactive surface provided by the high surface area to volume ratio [11]. Thus, the use of rice husk and straw as sources of CNCs provides another sustainable way to exploit these by-products and opens opportunities for new CNCs applications.

The present study presents a novel top-down approach for producing CNCs out of rice husk and straw through a one-pot synthesis, using hydrolysis at low sulphuric acid concentration and high temperature/pressure, and further evaluating their electrostructural modifications in the presence of metallic ions, aiming to access metal binding for possible use in bioremediation field.

In order to optimize CNCs formation from the hydrolyzed rice by-products suspension, different reagents and pHs were tested and analyzed through the Vis-absorbance spectrophotometry method to obtain ideal reagents concentration and $\mathrm{pH}$. Along with these data, dynamic light scattering (DLS) and Zeta potential measurements were used to verify which formulation resulted in a stable $\mathrm{CNC}$ colloidal suspension. Atomic force microscopy (AFM) and scanning electron microscopy (SEM) provided data on shape and size distribution of the CNC suspensions in the presence or absence of $\mathrm{Na}(\mathrm{I}), \mathrm{Cd}(\mathrm{II})$, or $\mathrm{Al}(\mathrm{III})$ ion solutions.

Electrical conductivity (EC) of the CNC suspensions was also evaluated in the presence or absence of the metal ions solution in order to determine the possible electrical behaviour changes and estimate the metal binding.

\section{Materials and Methods}

2.1. Treatment of Rice By-Products. Rice straw mixed with rice husk $(60 \mathrm{~g})$ was extensively washed with distilled water followed by two cycles of ethanol washing $(1: 1 \mathrm{v} / \mathrm{v})$ under agitation for $20 \mathrm{~min}$ and three cycles of ultrapure water washing for $15 \mathrm{~min}$ under mild magnetic stirring. Then, the material was dried at $60^{\circ} \mathrm{C}$ for $4 \mathrm{~h}$ followed by nitrogen freezing and maceration to form a thick powder. Sample hydrolysis was performed with $100 \mathrm{~mL}$ of $1 \%$ sulphuric acid solution in autoclave at $121^{\circ} \mathrm{C}$ for $20 \mathrm{~min}$. The resulting suspension was diluted in ultrapure water $1: 1(\mathrm{v} / \mathrm{v})$ and all $\mathrm{pH}$ values tested were adjusted using sodium hydroxide.

2.2. Synthesis of Cellulose Nanocrystals. Initially, nanoparticles formation from the hydrolysed rice husk and straw suspension (HR) was evaluated under different conditions for further selection of an optimized sample for scale-up and further characterization. The conditions used for particle formation varied in HR: water : ethanol $(\mathrm{v} / \mathrm{v} / \mathrm{v})$ content in different proportions. All of them were carried out in triplicate using $\mathrm{pH} 5,7,9$, or 11 and $0.1 \%$ glutaraldehyde (final concentration) was used as a cross-linking agent [12].

2.3. Spectrophotometric Analysis. Possible CNCs formation was monitored by absorption scanning (turbidity) using the ELx808 IU absorbance microplate reader (BioTek, USA) at the wavelengths of 405,490 , and $630 \mathrm{~nm}$ in $3 \mathrm{~min}$ intervals for 1 hour at $32^{\circ} \mathrm{C}$.

\subsection{Dynamic Light Scattering (DLS) and Zeta Potential.} Hydrodynamic diameters and Zeta potentials of CNCs were measured using a ZetaSizer Nano ZS (Malvern Instruments Ltd., UK) at a fixed scattering angle of $173^{\circ}$. The samples were diluted to $60 \%(\mathrm{v} / \mathrm{v})$ with ultrapure water and the measurements were carried out in triplicate.

2.5. Atomic Force Microscopy (AFM). AFM measurements of the CNCs were performed using a SPM-9600 atomic force microscope (Shimadzu, Japan) operated in air by dynamic phase mode. The analyzed samples were prepared by adding $1 \mu \mathrm{L}$ of each sample on freshly cleaved mica at room temperature (RT, approximately $22^{\circ} \mathrm{C}$ ) and air drying after deposition. The images were scanned using a cantilever with tip curvature radius of less than $10 \mathrm{~nm}$ (type PPP-CNHR-20, Nanosensors). The scanning rate was set at $1 \mathrm{~Hz}$, sampling resolution of $512 \times 512$, and a scan size of $10 \mu \mathrm{m} \times 10 \mu \mathrm{m}$ for standard images. Image analysis of height, length, and width data was calculated by average $Z$, maximum diameter, and pattern width, respectively, obtained using SPM Manager 3.0 particle analysis software (Shimadzu). Images used for data processing were height trace types and the background level on the $x$-axis and the plane fit auto algorithms were applied for tilt correction.

2.6. Scanning Electron Microscopy (SEM). Samples were fixed by exposure to $\mathrm{OsO}_{4}$ vapour, sputter-coated with gold (Balzers Union SCD-040, Electron Microscopy Sciences, USA), and examined with a scanning electron microscope JEM 840A (Jeol, USA).

2.7. Analysis of Electrical Conductivity. Firstly, for each metal, a stock solution of $50 \mathrm{mg} / \mathrm{L}$ was prepared using ultrapure water and a calibration curve of electrical conductivity (EC) to determine the electrical behaviour was acquired. While taking ion hydration from the chlorides into consideration, the final ion molar concentration for each metal stock solution was $0.86,0.25$, and $0.21 \mathrm{~mol} \cdot \mathrm{L}^{-1}$ for $\mathrm{Na}^{+}, \mathrm{Cd}^{2+}$, and $\mathrm{Al}^{3+}$, respectively.

To access the CNC suspensions electrical behaviours, EC analyses of the colloidal suspensions in different volumes were performed, following the same methodology used in the metal calibration curves. The CNC samples were maintained at $30^{\circ} \mathrm{C}$ for $1 \mathrm{~h}$ and then centrifuged for $10 \mathrm{~min}$ (RCF $=$ $12,054 \mathrm{~g}$ ) before EC analysis. Another EC measurement was obtained after 24 hours of incubation at $30^{\circ} \mathrm{C}$. EC of the CNC 
and metal ion solutions were evaluated by a bench conductivity meter model Q795A (Quimis, Brazil). All measurements were obtained using $1.5 \mathrm{~mL}$ of each reaction solution at RT and had a wait time of $15 \mathrm{~s}$ for stabilization of the equipment.

\section{Results and Discussion}

3.1. Optimization of CNCs Production. The reaction of hydrolysis presented in this study constitutes a simple onepot synthesis of CNCs, without the need of further steps for purification (i.e., dialysis and/or filtration). The high temperature/pressure allows the use of a much lower acid concentration (1\%), which is usually $45-60 \%$ [13]. After hydrolysis, Vis-absorbance analysis at $630 \mathrm{~nm}$ was performed to evaluate CNCs formation/stabilization in order to further optimize reagents concentration and $\mathrm{pH}$ level. All combinations of the HR mixed only with water did not present a stable growth, whereas HRs mixed with ethanol showed particle formation (Figure 1(a)), mainly the one with $\mathrm{HR}$ : water : ethanol 1:1:2(v/v/v). Results of $\mathrm{pH}$ variations for this solution 1:1:2 are presented in Figure 1(b). This sample was then analyzed through DLS to determine which $\mathrm{pH}$ was more suitable for higher scale production.

The suspensions of CNCs produced at different $\mathrm{pHs}$ contained large particle agglomerates, as indicated by a polydispersity index higher than 0.7 along with a $Z$-average higher than $600 \mathrm{~d} \cdot \mathrm{nm}$. Zeta potential values for the reaction mixture with pHs 5, 7, 9, and 11 were $-26.1,-22.4,-39.5$, and $-28.3 \mathrm{mV}$, respectively. The presence of such large agglomerates might have dominated the obtained signal, masking the possible presence of smaller CNCs. Thus, in order to correctly estimate the CNCs subpopulations, the average particle distribution in number percentage was calculated and presented in Figures 1(c) to 1(f).

Along with the nanosized structures revealed by the DLS analyses, high value of Zeta potential, and success particle formation in Vis spectrum analysis, the HR: water : ethanol $1: 1: 2(\mathrm{v} / \mathrm{v} / \mathrm{v})$ condition at $\mathrm{pH} 9$ was selected for a $60 \mathrm{x}$ higher scale-up CNCs production, which will hereafter be termed as ${ }^{*} \mathrm{CNC}$.

3.2. Characterization of ${ }^{*} \mathrm{CNC}$. The ${ }^{*} \mathrm{CNCs}$ produced at a higher scale showed a consistent formation in Vis-absorbance spectral analysis (Figure 2(a)), and DLS indicated a $Z$ average of $454.0 \pm 39.2 \mathrm{~d} \cdot \mathrm{nm}$, Zeta potential of $-18.9 \mathrm{mV}$, and polydispersity index of $0.74 \pm 0.05$. These data indicated that there is still particle agglomeration, but ${ }^{*} \mathrm{CNCs}$ diameters distribution (Figure 2(b)) showed smaller particles sizes than those of the suspensions previously evaluated.

For structural characterization, ${ }^{*} \mathrm{CNC}$ sample was analyzed in its concentrated and in a $5 x$ diluted suspension with ultrapure water. Figures 3(a) and 3(b) show that, in the concentrated suspension, the nanocrystals exhibit agglomerates, forming a condensed network of fractal structures probably due to ionic strength effects. In the diluted suspensions (Figure 3(c)), the structures were dispersed in a suspension and presented as rod-like CNCs, similar in shape to the whiskers from cotton and Avicel, a commercial microcrystalline cellulose [14].
The average height, length, and width (Figures 3(d), 3(e), and 3(f)) for the diluted nanocrystals in a colloidal suspension were 11.0, 191.2, and $97.2 \mathrm{~nm}$, respectively, therefore having an aspect ratio (length/width) of 2 , as investigated by AFM. The aspect ratio of CNCs in aqueous suspensions can vary from 1 to about 100 [11]. The morphological characteristics of CNCs are dependent on the origin of cellulose and on the acid hydrolysis conditions, which in this case were mild. Nevertheless, the presented ${ }^{*} \mathrm{CNC}$ sample was similar in the parameters of height and length to the rice straw and husk synthetized CNCs described by other studies [4, 15]. It is also worth considering that DLS estimates particle size based on a spherical model, so if the sample is not agglomerated, the particle size would still be at least the size of the length.

3.3. Metal Association Analysis by AFM and SEM. Atomic force microscopy (AFM) and scanning electron microscopy (SEM) were used to assess possible metal association to ${ }^{*} \mathrm{CNC}$ sample (Figure 4). All the three metals were analyzed from their stock solutions and all formed nanoscale structures after air-drying for microscopic analysis. To assess possible ${ }^{*} \mathrm{CNCs}$ topographic changes in metal presence, the ${ }^{*} \mathrm{CNC} 5 \mathrm{x}$ suspension diluted with ultrapure water was mixed $1: 1(\mathrm{v} / \mathrm{v})$ with each metal stock solution and imaged.

3.3.1. $\mathrm{Na}(\mathrm{I})$. Sodium particles were cylinder-shaped with an average height of $27.4 \mathrm{~nm}$ (Figure 4(a)) but also easily agglomerated, forming large structures. In the presence of ${ }^{*} \mathrm{CNC}$, the structures showed a rounder shape and there was a decrease in the average height distribution to $5.7 \mathrm{~nm}$ (Figure 4(d)). In particular after hydrolysis, CNCs had negatively charged groups on their surfaces when in an aqueous media [4], which could attract the sodium ions, making them leave the state of particle agglomeration. In addition, we could hypothesize that the fact of sodium being a monovalent cation of low molecular weight could also facilitate binding to ${ }^{*} \mathrm{CNC}$ more than the other metals and this hypothesis was further tested and confirmed.

3.3.2. $C d(I I)$. Cadmium particles had a spherical shape and an average height of $4.2 \mathrm{~nm}$ (Figure 4(b)). When with ${ }^{*} \mathrm{CNC}$ in suspension, some particles adopted an elongated shape and formed agglomerates, but in the background there were still some isolated cadmium particles (Figure 4(e)). Data from height distribution shows that $\mathrm{Cd}$ ions have a low affinity to the ${ }^{*} \mathrm{CNC}$, since most particles had $3.7 \mathrm{~nm}$, which is close to the size of the structures observed in free $\mathrm{Cd}$.

3.3.3. Al(III). Aluminium particles present in free form also had a spherical shape (Figure 4(c)) but had heterogeneous heights, forming two subpopulations of particles, one with an average height of 12.4 and the other of $21.4 \mathrm{~nm}$. In the presence of ${ }^{*} \mathrm{CNC}$, the formed CNCs adopted an elliptical form, with height predominant at $13.7 \mathrm{~nm}$ (Figure 4(f)), suggesting that only some $\mathrm{Al}$ were associated with the ${ }^{*} \mathrm{CNC}$.

3.4. Electrical Conductivity Analysis. All metal ions presented a linear EC rate dependent on the concentration, as exhibited in Figure 5(a), while ${ }^{*}$ CNCs EC rose with higher sample 


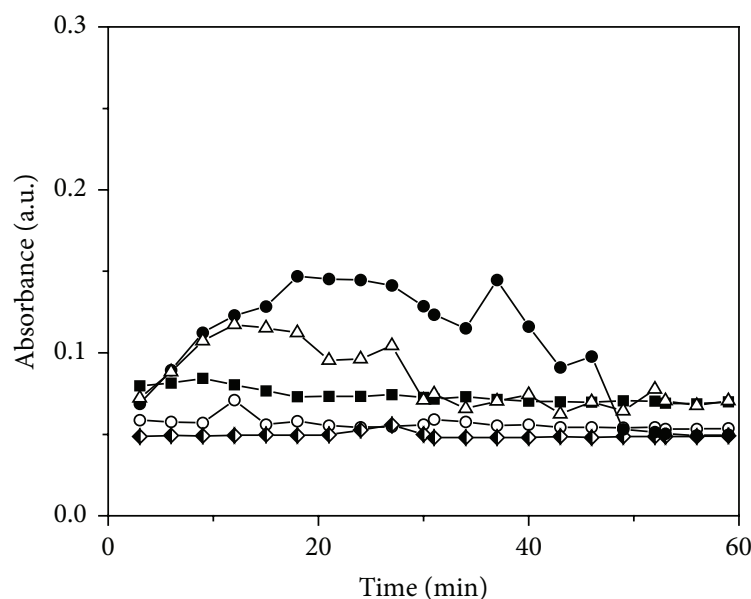

- - $3: 1: 0$

-o- 1:1:0

$-1: 3: 0$

(a)

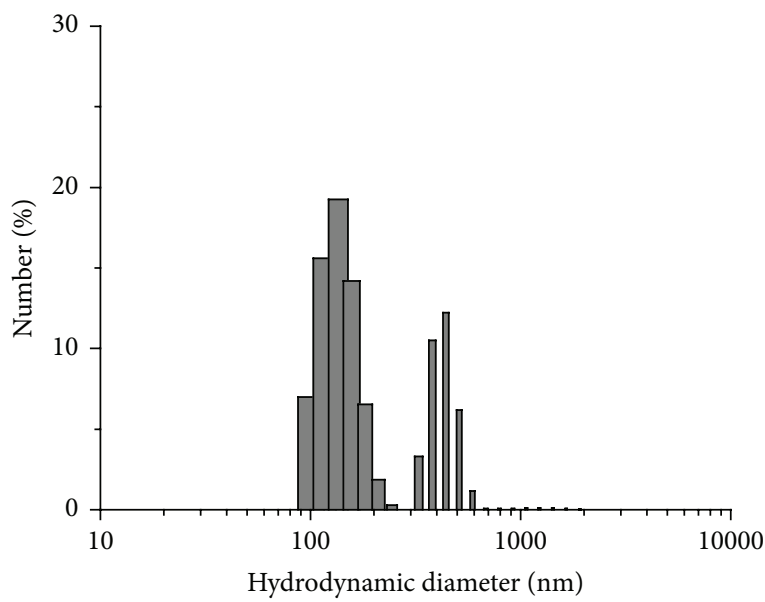

(c)

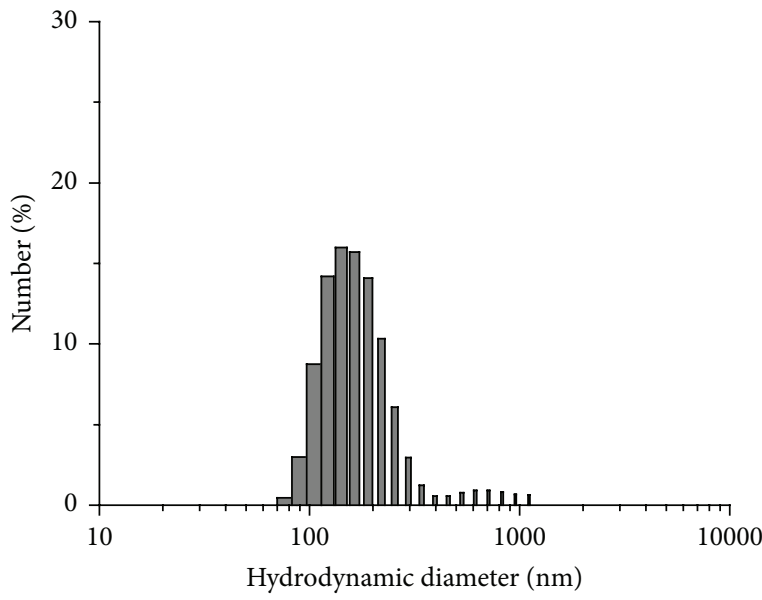

(e)

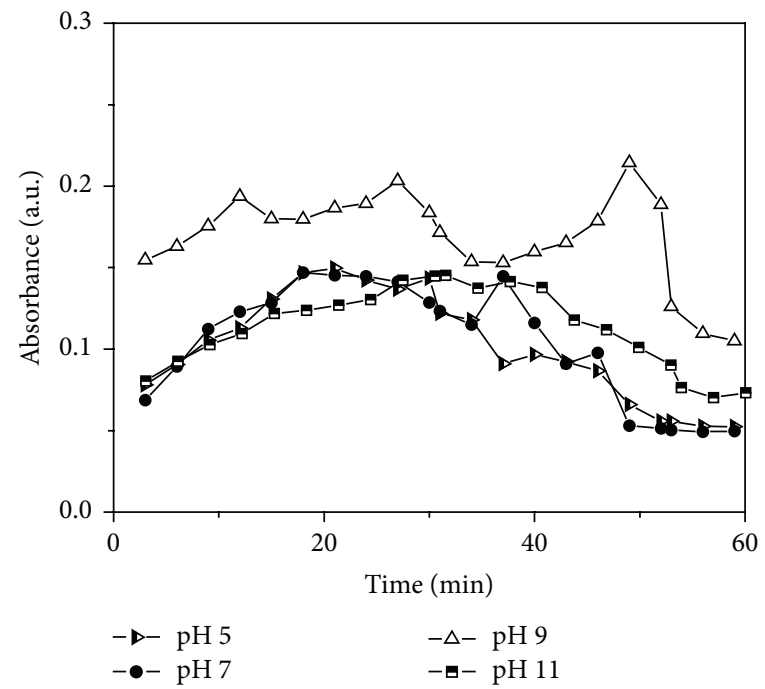

(b)

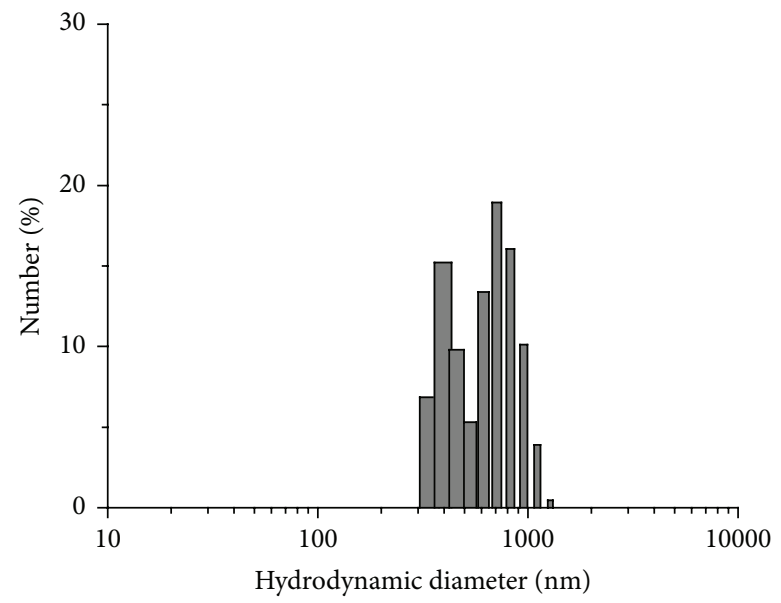

(d)

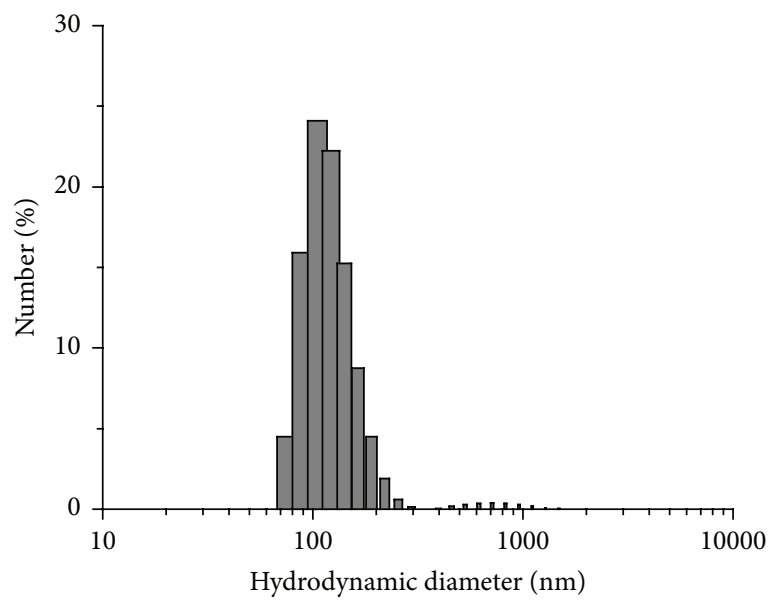

(f)

FIGURE 1: Spectrophotometric analysis of CNCs formation with different reagent ratios or reaction pH and analyses of CNCs size obtained by dynamic light scattering. Representative Vis-absorbance spectra at $630 \mathrm{~nm}$ of (a) the tested conditions according to the proportions of hydrolysed rice husk and straw suspension (HR), water, and ethanol at $\mathrm{pH} 7$ and (b) of the HR: water : ethanol 1:1:2 (v/v/v) suspension at different pHs. Histograms of the hydrodynamic diameter using the number of events distribution of the suspensions at pHs 5 (c), 7 (d), 9 (e), and 11 (f). 


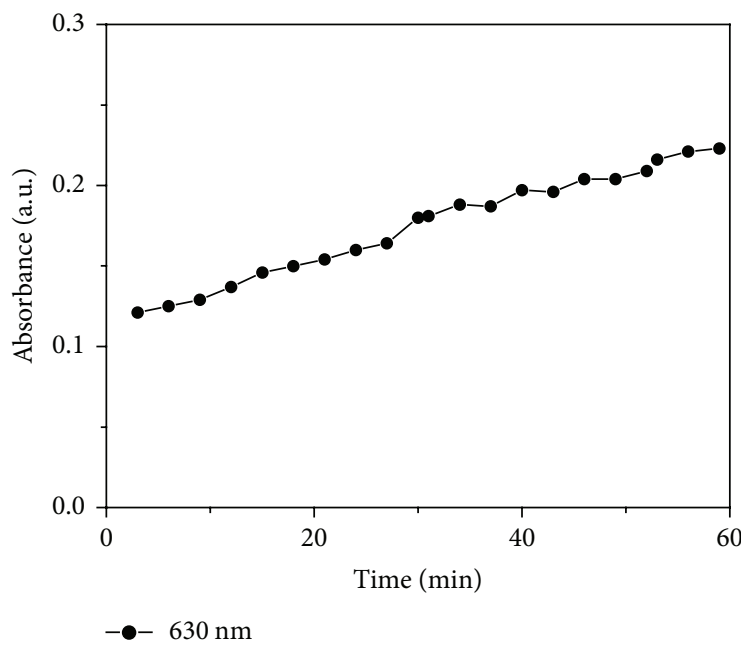

(a)

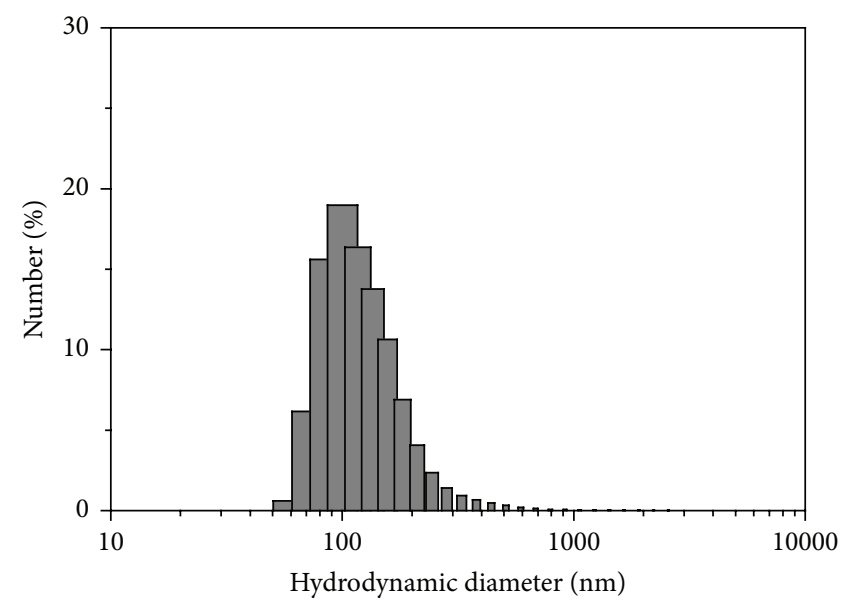

(b)

Figure 2: *CNC spectrophotometric and dynamic light scattering analyses. (a) Representative Vis-absorbance spectra at $630 \mathrm{~nm}$ of ${ }^{*} \mathrm{CNC}$ particle formation. (b) Histogram representing the hydrodynamic diameter classes of ${ }^{*} \mathrm{CNC}$ using number of events data. The average diameter was $120.7 \pm 35.4 \mathrm{~nm}$.
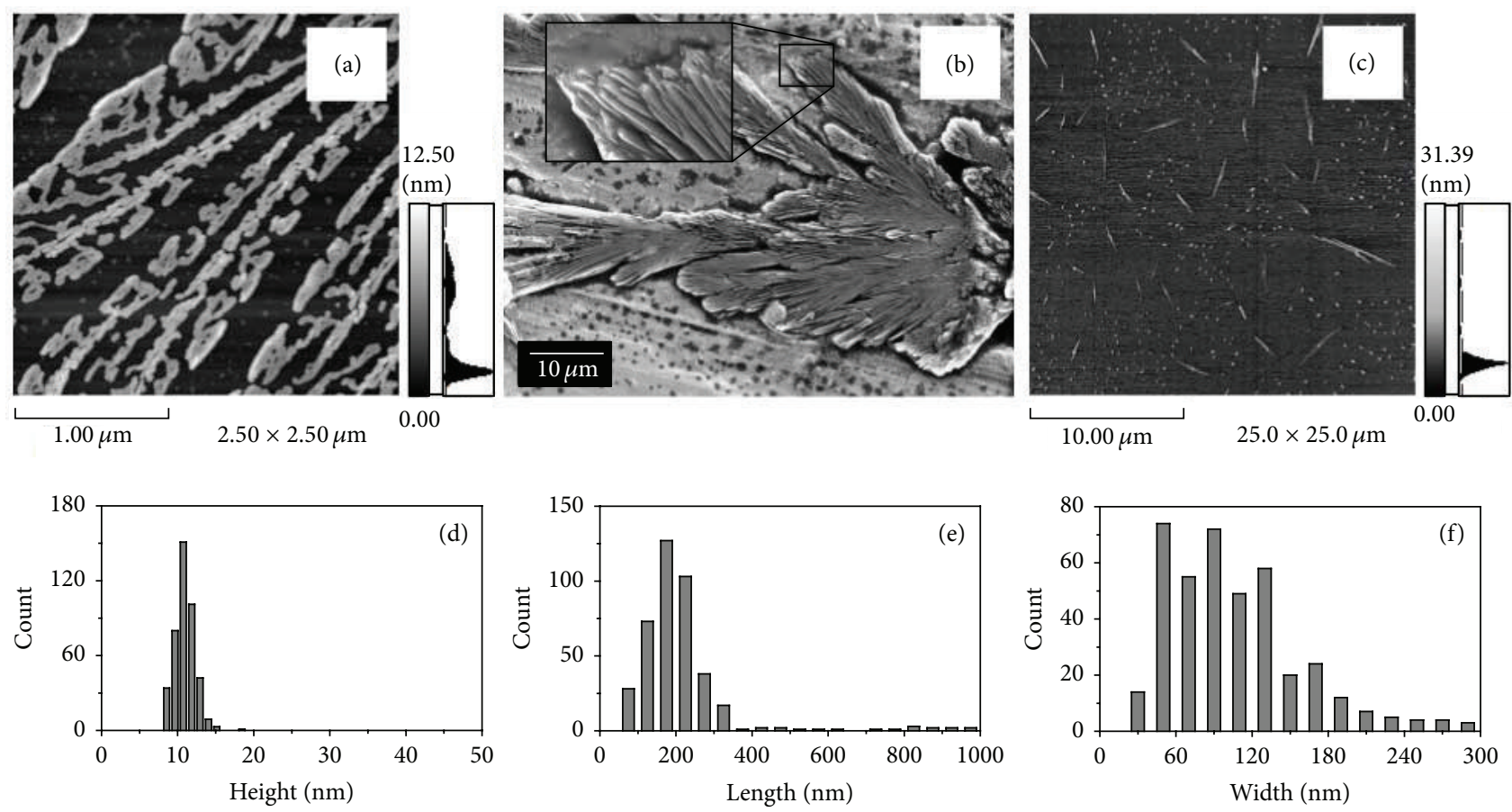

FIgURE 3: (a) Atomic force microscopy (AFM) and (b) scanning electron microscopy (SEM) images of the * ${ }^{*} \mathrm{CNC}$ sample in the concentrated solution in water. (c) AFM topographic image of the ${ }^{*} \mathrm{CNC}$ in the $5 \mathrm{x}$ diluted solution in water and the AFM size distribution histograms corresponding to (d) height, (e) length, and (f) width of the particles.

volume tested. The particle agglomerates, formed when the ${ }^{*} \mathrm{CNC}$ solution was more concentrated, had a higher EC. CNCs, due to their size in nanoscale, not only possess high mechanical strength but also have significant changes in electrical, dielectric, and conductive properties [11].

By calculating the difference in the EC of the ${ }^{*} \mathrm{CNC}$ suspension with or without the metal ions and dividing it by the correspondent metal stock solutions EC, the percentage of metal ions binding to ${ }^{*} \mathrm{CNC}$ in solution can be estimated. This was based on the lowest dilution of ${ }^{*} \mathrm{CNC}$ (i.e., $1: 20 \mathrm{v} / \mathrm{v}$ ) because its electrical behaviour does not follow a linear pattern. Data on the EC is shown in Table 1.

Through this approach, the percentage of metal binding to ${ }^{*} \mathrm{CNC}$ in aqueous suspensions was $79.67,22.09$, and 

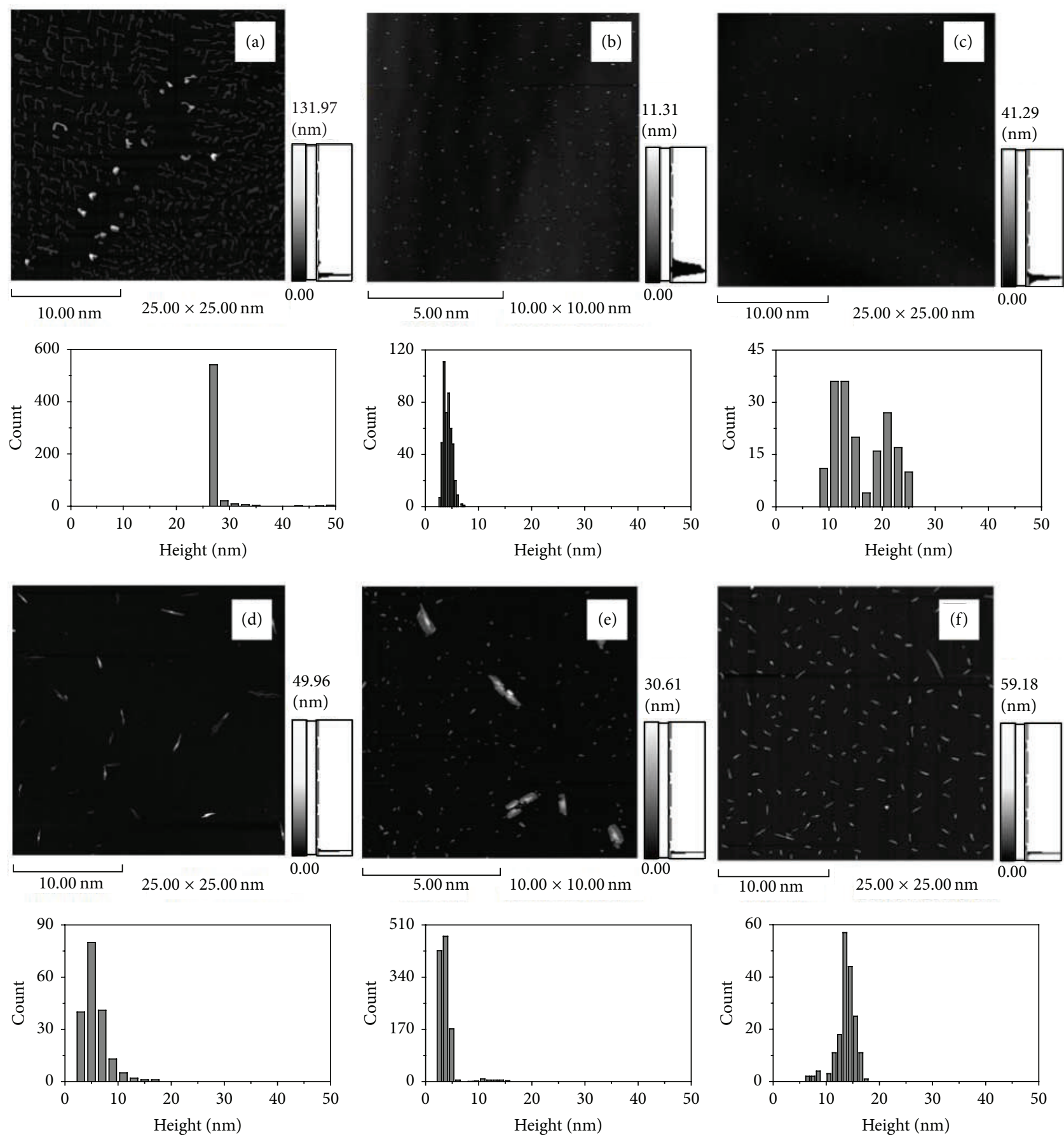

Figure 4: Analyses of nanoparticles size and cellulose nanocrystals-metal interaction imaged by atomic force microscopy (AFM). Representative AFM topographic images of the metal stock solution without, (a), (b), and (c) for $\mathrm{Na}$ (I), Cd(II), and Al(III), respectively, and with the ${ }^{*} \mathrm{CNC}$ in aqueous suspension, (d), (e), and (f) for $\mathrm{Na}(\mathrm{I}), \mathrm{Cd}(\mathrm{II})$, and $\mathrm{Al}(\mathrm{III})$, respectively. Below each AFM image is its correspondent particle height distribution histogram and the average particle height is also noted. The metal ion samples formed nanostructures which are observed at the background in different extents when in the ${ }^{*} \mathrm{CNCs}$ presence, according to the amount of metal that bound to the CNCs. All AFM measurements were performed by dynamic mode in order to minimize tip-particle lateral interaction.

33.18 for $\mathrm{Na}^{+}, \mathrm{Cd}^{2+}$, and $\mathrm{Al}^{3+}$, respectively. This indicates that ${ }^{*} \mathrm{CNC}$ bound to the three metal ions and the observed values corroborate the AFM analysis. Additionally, EC was weakly affected by sample incubation by 24 hours (data not shown).

\section{Conclusions}

Cellulose-derived whisker from rice straw and husk was produced through a one-pot synthesis with acid hydrolysis at high temperature/pressure. The synthesized CNCs were 


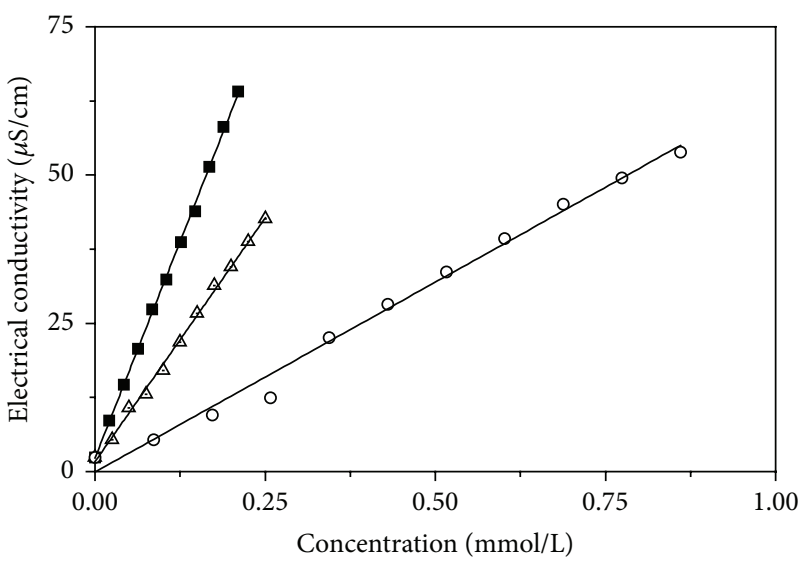

$\mathrm{Al}$

$\triangle \mathrm{Cd}$

○ $\mathrm{Na}$

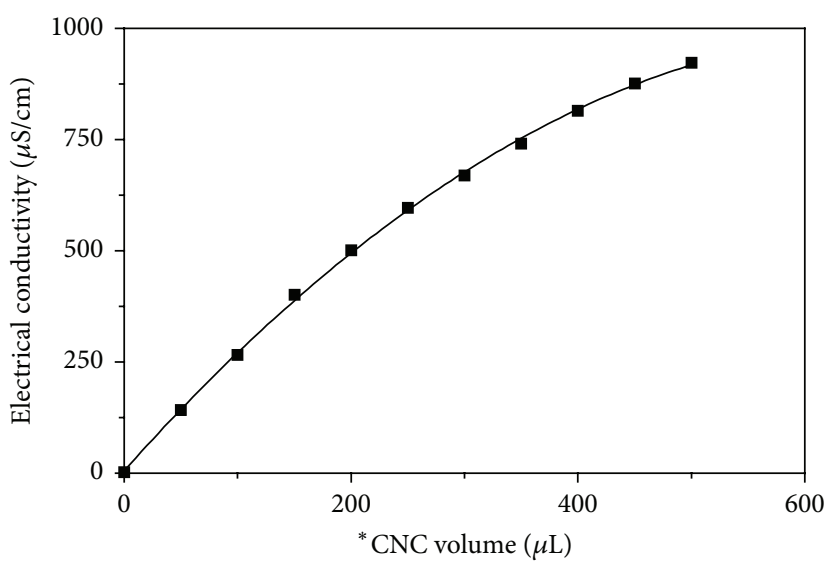

(b)

Figure 5: (a) Metal ion solution electrical conductivities calibration curves. $R^{2}$ for $\mathrm{Na}^{+}, \mathrm{Cd}^{2+}$, and $\mathrm{Al}^{3+}$ were $0.9904,0.9971$, and 0.9991 , respectively. (b) ${ }^{*} \mathrm{CNC}$ 's electrical conductivity behaviour according to its volume evaluated.

TABLE 1: Electrical conductivities $(\mu \mathrm{S} / \mathrm{cm})$ of $\mathrm{Al}^{3+}, \mathrm{Cd}^{2+}$, and $\mathrm{Na}^{+}$in the presence of ${ }^{*} \mathrm{CNC}$ in aqueous suspension.

\begin{tabular}{|c|c|c|c|}
\hline${ }^{*} \mathrm{CNC}$ dilutions ${ }^{\mathrm{a}}$ & $\mathrm{Al}^{3+}$ & $\mathrm{Cd}^{2+}$ & $\mathrm{Na}^{+}$ \\
\hline 0 & 63.3 & 43.0 & 54.6 \\
\hline $1: 20$ & 174.5 & 163 & 197 \\
\hline $1: 4$ & 595 & 613 & 622 \\
\hline $1: 2$ & 957 & 943 & 976 \\
\hline
\end{tabular}

a* CNC diluted suspensions were tested with each metal stock solution in a $1: 1(\mathrm{v} / \mathrm{v})$.

stable and presented rod-like shape. In presence of metals, AFM/SEM and EC data show, by size, shape, and charge changes, that the CNCs bind to metals. Results from AFM corroborate EC data, indicating that the produced CNCs have more affinity in binding sodium but also bind cadmium and aluminium ions. Data suggest that the use of these CNCs in the bioremediation field is promising, both in metal sorption from wastewater or as an alternative for water desalination.

\section{Conflict of Interests}

The authors declare that there is no conflict of interests regarding the publication of this paper.

\section{Acknowledgments}

The authors wish to thank CAPES (process no. 23038.019088/ 2009-58), CNPq (process nos. 555175/2005-7, 302018/20085, 305637/2011-8, 563802/2010-3, 480286/2012-4, and 306413/ 2014-0), FAPDF, and Embrapa for financial support and fellowships.

\section{References}

[1] G. A. Joanitti and L. P. Silva, "The emerging potential of byproducts as platforms for drug delivery systems," Current Drug Targets, vol. 15, no. 5, pp. 478-485, 2014.

[2] L. Goetz, A. Mathew, K. Oksman, P. Gatenholm, and A. J. Ragauskas, "A novel nanocomposite film prepared from crosslinked cellulosic whiskers," Carbohydrate Polymers, vol. 75, no. 1, pp. 85-89, 2009.

[3] S. J. Eichhorn, A. Dufresne, M. Aranguren et al., "Review: current international research into cellulose nanofibres and nanocomposites," Journal of Materials Science, vol. 45, no. 1, pp. $1-33,2010$.

[4] P. Lu and Y.-L. Hsieh, "Preparation and characterization of cellulose nanocrystals from rice straw," Carbohydrate Polymers, vol. 87, no. 1, pp. 564-573, 2012.

[5] Y. Habibi, L. A. Lucia, and O. J. Rojas, "Cellulose nanocrystals: chemistry, self-assembly, and applications," Chemical Reviews, vol. 110, no. 6, pp. 3479-3500, 2010.

[6] M. Ioelovich, "Optimal conditions for isolation of nanocrystalline cellulose particles," Nanoscience and Nanotechnology, vol. 2, no. 2, pp. 9-13, 2012.

[7] U. Kumar, "Agricultural products and by-products as a low cost adsorbent for heavy metal removal from water and wastewater: a review," Scientific Research and Essays, vol. 1, no. 2, pp. 33-37, 2006.

[8] M. Ajmal, R. A. K. Rao, S. Anwar, J. Ahmad, and R. Ahmad, "Adsorption studies on rice husk: removal and recovery of Cd(II) from wastewater," Bioresource Technology, vol. 86, no. 2, pp. 147-149, 2003.

[9] U. Kumar and M. Bandyopadhyay, "Sorption of cadmium from aqueous solution using pretreated rice husk," Bioresource Technology, vol. 97, no. 1, pp. 104-109, 2006.

[10] L. Shao, Z. X. Xu, W. Jin, and H. L. Yin, "Rice husk as carbon source and biofilm carrier for water denitrification," Polish Journal of Environmental Studies, vol. 18, no. 4, pp. 693-699, 2009. 
[11] M. A. S. A. Samir, F. Alloin, and A. Dufresne, "Review of recent research into cellulosic whiskers, their properties and their application in nanocomposite field," Biomacromolecules, vol. 6, no. 2, pp. 612-626, 2005.

[12] I. Migneault, C. Dartiguenave, M. J. Bertrand, and K. C. Waldron, "Glutaraldehyde: behavior in aqueous solution, reaction with proteins, and application to enzyme crosslinking," BioTechniques, vol. 37, no. 5, pp. 790-802, 2004.

[13] D. De Jesus Silva and M. L. O. D’Almeida, "Cellulose whiskers," Revista O Papel, vol. 70, no. 7, pp. 34-52, 2009.

[14] S. Elazzouzi-Hafraoui, Y. Nishiyama, J.-L. Putaux, L. Heux, F. Dubreuil, and C. Rochas, "The shape and size distribution of crystalline nanoparticles prepared by acid hydrolysis of native cellulose," Biomacromolecules, vol. 9, no. 1, pp. 57-65, 2008.

[15] S. M. L. Rosa, N. Rehman, M. I. G. De Miranda, S. M. B. Nachtigall, and C. I. D. Bica, "Chlorine-free extraction of cellulose from rice husk and whisker isolation," Carbohydrate Polymers, vol. 87, no. 2, pp. 1131-1138, 2012. 

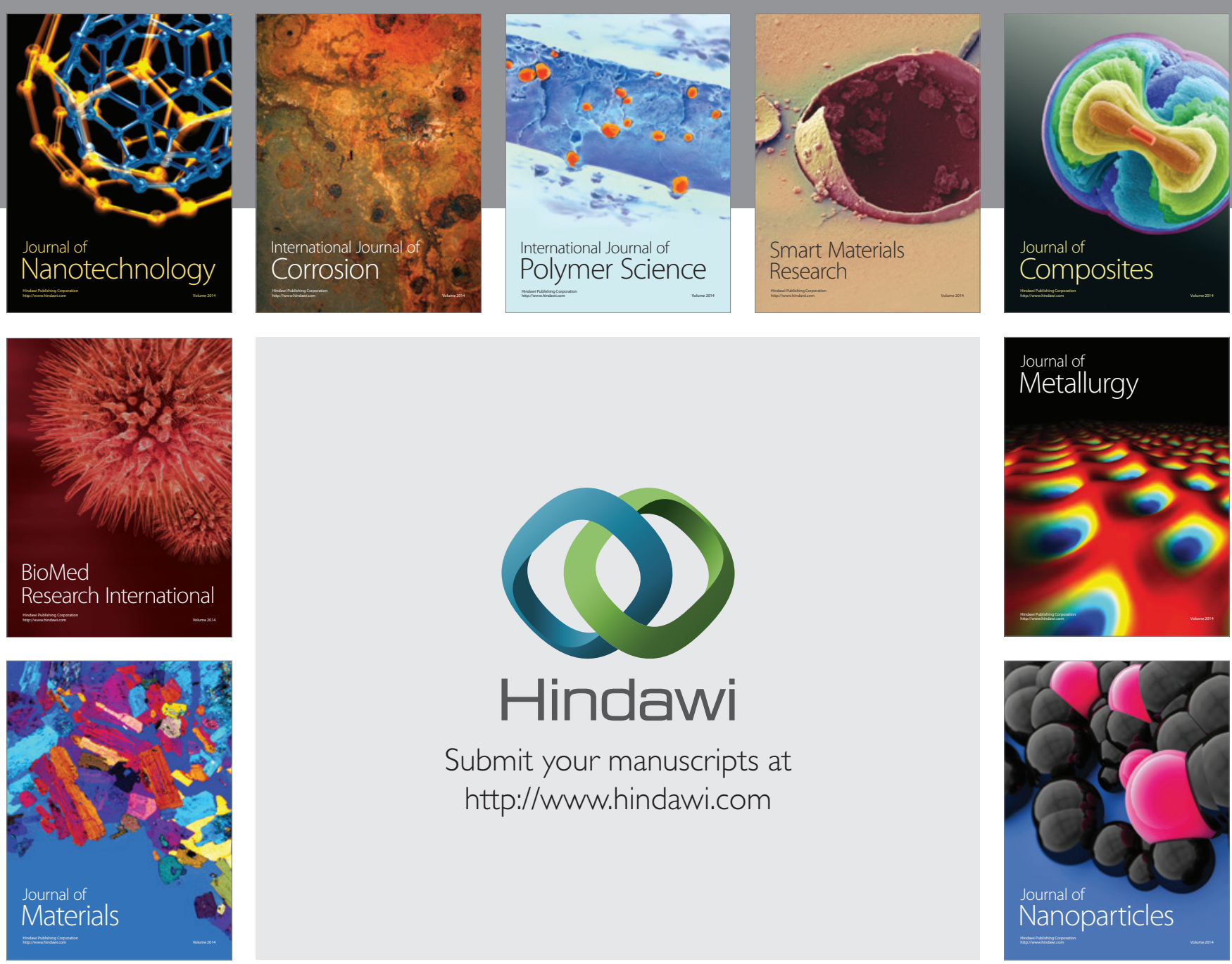

Submit your manuscripts at http://www.hindawi.com
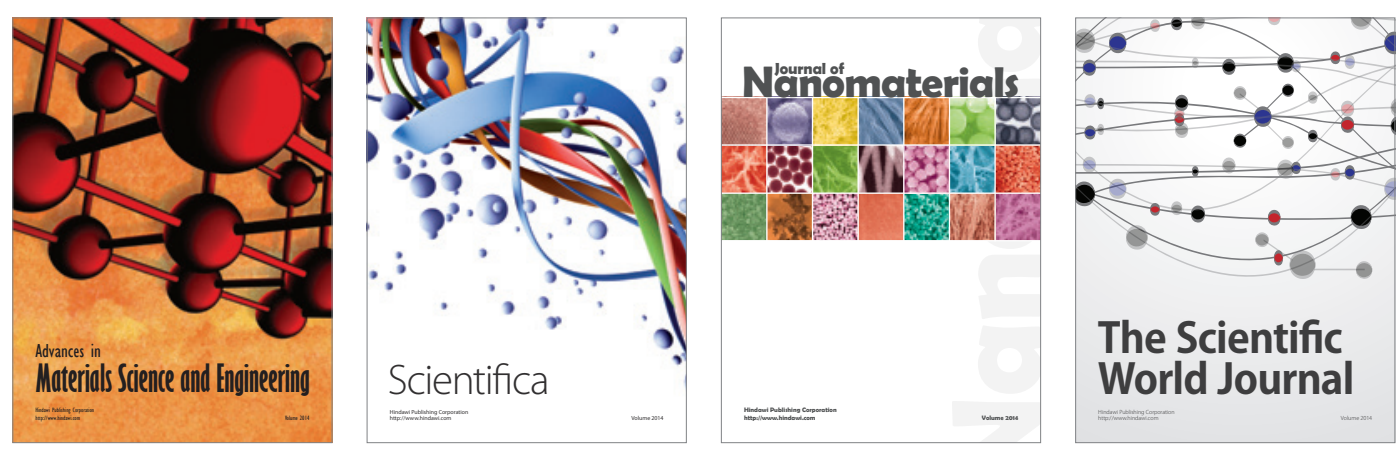

\section{The Scientific World Journal}
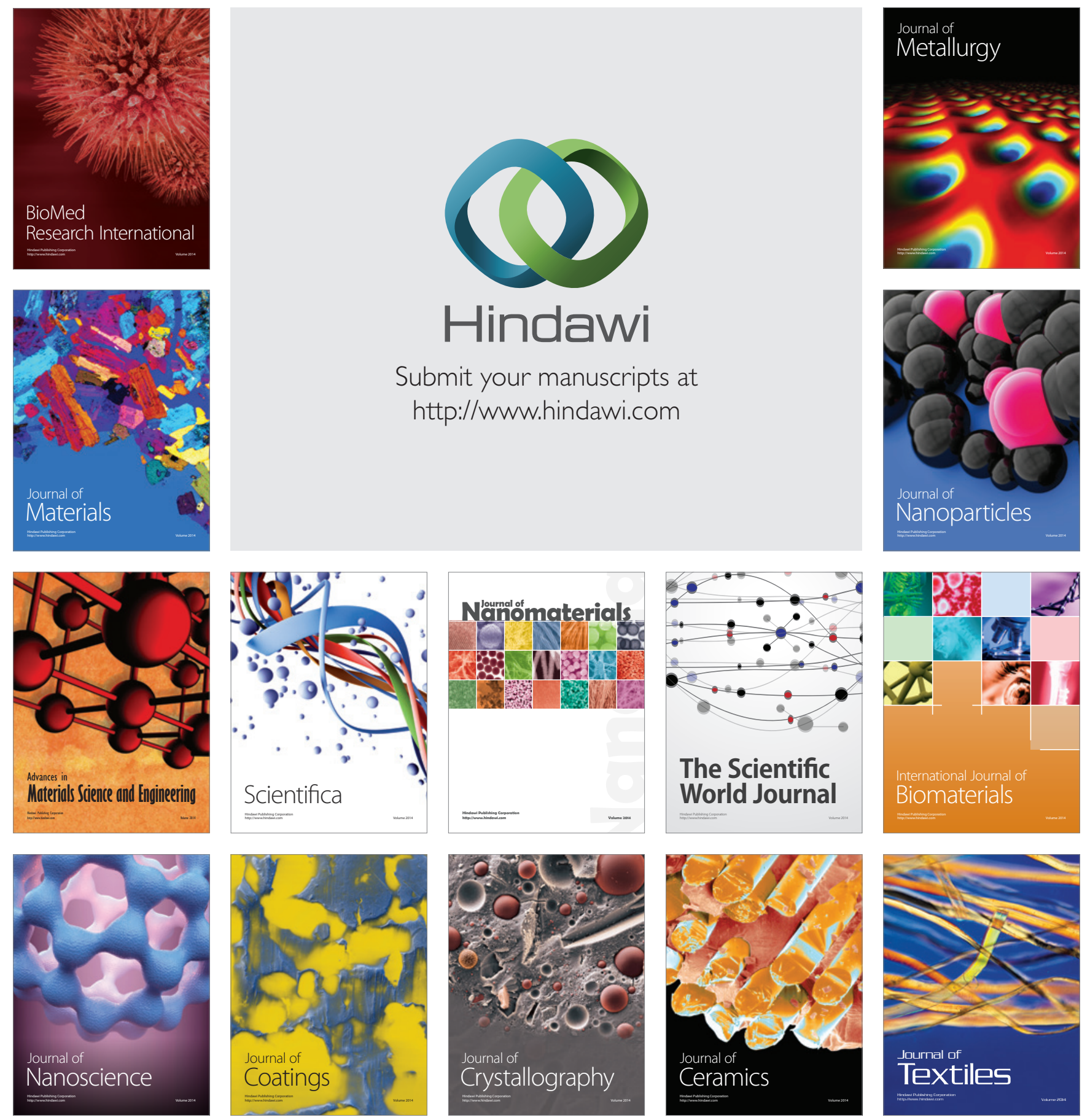